\title{
Naciste pintada de Carmen Berenguer o el desplazamiento de los géneros literarios/sexuales
}

\author{
Naciste pintada by $\mathrm{C}$ armen Berenguer or \\ the movement of literary/sexual genders
}

\section{LORENA GARRID O DONOSO}

Universidad de Chile. Santiago, Chile

lorenagarridod@gmail.com

\section{RESUMEN}

El siguiente artículo propone una lectura del libro $\mathrm{N}$ aciste pintada de $\mathrm{C}$ armen Berenguer, desde el punto de vista de los géneros literarios/sexuales. Berenguer desplaza el límite hegemónico de los ámbitos público/privado delos géneros sexuales, a través de una ruptura en el orden de los géneros literarios, siendo el testimonio como género referencial el que atraviesa todo el discurso.

Palabras claves. N aciste pintada, Carmen Berenguer, géneros literarios, géneros sexuales, testimonio.

\section{ABST RACT}

Thefollowing article proposesa reading of the book $\mathrm{N}$ acistepintada by $\mathrm{C}$ armen Berenguer, from a literary/sexual gender's point of view. Berenguer moves the hegemonic limit of the private/public extents of sexual genders, through a break in theliterary genre orders, where the testimony as a referential genre is the one which goes through the entire discourse.

Keywords: N aciste pintada, Carmen Berenguer, literary genres, sexual genders, testimonio. Recibido: 28-02-2008. Aceptado: 22-04-2008.

— L SIGUIEN TE trabajo propone un análisis del libro N aciste pintada de Car- men Berenguer, desde el punto de vista de los géneros, en un amplio sentido del término. D esde el punto de vista literario, no queda claro en qué lugar 
situar a esta obra. La portada del libro clasifica al texto de "recados y poesía". La propia Berenguer afirma en un artículo que su intención era hacer "un registro del recado" (2000), pero luego en la introducción de su libro, habla de "testimonio". ¿A qué género real mente pertenece esta obra? ¿Es posible clasificarla?

$\mathrm{N}$ uestra hipótesis es que $\mathrm{N}$ aci ste pintada es un texto que rompe con la hegemonía de los géneros y que está atravesado por el testimonio como base del discurso. Esta ruptura en los géneros literarios le serviría a Berenguer para lograr también un desplazamiento del género sexual. C reemosqueel texto deBerenguer, precisamente basándose en el lugar que el testimonio ocupa en el período postmoderno, intenta ser una narrativa de la resistencia que dé voz a las mujeres y las re-sitúe en la historia permitiéndoles salir del espacio privado hacia el espacio público.

Para nuestro análisis abordaremos primero el problema de los géneros discursivos que priman en cada una de las partes de $\mathrm{N}$ aciste pintada, para luego centrarnos en cómo éstos alteran y producen un desplazamiento no sólo literario sino también en el discurso de los géneros sexuales.

\section{FRACTURA DE LOS GENEROS}

M ostrar que N aciste pintada rompe con la hegemonía de los géneros, no es una tarea difícil. En sus distintas partes Berenguer se pasea por la poesía, la narración, la crónica y las cartas desde la prisión. Esta fractura es algo que Lyotard (2000) identifica como una característica de la postmodernidad: el rechazo a una gran narrativa, lo que va a permitir el surgimiento del relato testimonial. Esta pérdida de una gran narrativa en Chile, tal como advierte Leonidas M orales (2001), adquiere una dimensión especial en el período dictatorial y postdictatorial en Chile, momento que en los géneros ficcionales "precipitó y aceleró procesos erosivos que venían dándose simultáneamente a nivel del sujeto (de su identidad) y del discurso (abandono y fragmentación de su linealidad)" (37).

Esta fragmentación, que es evidente en $\mathrm{N}$ aciste pintada, adquiere distintas formas en las tres partes que la componen: Casa cotidiana, Casa de la poesía y Casa inmóvil. La primera parte, Casa cotidiana, está constituida por poemas que relatan la vida y las percepciones del paisaje de la Plaza I talia (Santiago) en el presente, hechas por la hablante, que adopta la forma de narradora. D esde ahí hace un relato de la ciudad y de la política nacional. D e hecho lleva el subtítulo de "M etáforas caseras". Sobre cuál es el género a que corresponde esta parte, no hay duda que es al de la poesía, aunque no en su concepción clásica, sino que intercalando narraciones entre estrofas o entre versos. 
La segunda parte o C asa de la poesía se divide a su vez en cuatro secciones cuyo tema común es el prostíbulo como escenario y la historia de distintas prostitutas, siendo la protagonista de las tres primeras Brenda, y de la última, distintas prostitutas que cuentan sus historias. Esta parte será de gran importancia en nuestro análisis, porque es donde la presencia del relato testimonial comienza a adquirir fuerza.

Si bien la primera sección de Casa de la poesía se puede aun considerar un texto poético, ya la segunda parte no lo es, y la autora lo deja claro desde el título "Breve narración sobre su ausencia en los motivos nacionales". El texto, efectivamente, cumple con estas expectativas y adquiere esa condición; es un relato en prosa escrito en tercera persona. Incluso la diagramación del texto es diferente, y la narradora nos habla de personajes, trama y antagonista. El texto es casi una parodia de lo que es una novela. En ella, a la protagonista Brenda se agregan al gunas de sus amigas: $\mathrm{N}$ ina, la allegada Chona y las tías de Brenda.

En la tercera sección de C asa de la poesía, "B reve narración de sus motivos íntimos", Brenda cuenta su historia en primera persona, utilizando la forma de testimonio. La cuarta sección de esta segunda parte se titula "La distancia entre las M artitas, Anitas y Elenitas". Esta parte está precedida por un epígrafe de Walter Benjamin sobre la prostitución y la voz de una narradora que introduce los relatos que vendrán a continuación. La narradora denomina a estos relatos biografías: "H ablamos entre mujeres de la biografía considerándola inquietante" (131), pero al estar narradas en primera persona, seacercan más ala autobio-

grafía y al relato testimonial. Estos consisten en cuatro relatos de prostitutas de distintas edades que cuentan cómo tuvieron que iniciarse en la prostitución. D entro del último relato, la mujer que cuenta su historia la termina diciendo: "Aquí en medio de la calle está el burdel de la calle donde ocurrió un crimen". La afirmación da paso a un relato con forma de crónica en la que el narrador comenta la noticia de un crimen ocurrido en un prostíbulo y cómo apareció consignado en los diarios. De hecho aparece un recorte de la noticia acompañando a esta crónica. Luego aparecen los testimonios de los implicados en el hecho policial.

Todavía en la cuarta sección de Casa de la poesía aparece otra fecha y el seguimiento a la primera noticia. 0 tra vez hay un recorte de diario y los testimonios de los implicados. Luego, y sin previo aviso, aparecen fragmentos de testimonios de otras prostitutas, intercalados con noticias extraídas del diario La Cuarta en forma de pastiche, todas relacionadas con crímenes pasionales, de maltrato y violación a mujeres y delitos sexuales.

Para terminar, la última parte del libro de Berenguer se titula C asa Inmóvil y lleva por subtítulo "Recados de la prisión", que son los testimonios de al menos quince prisioneras políticas durante la dictadura de Pinochet. Los relatos están 
organizados bajo distintos temas, cada uno con un título, pero que intercalan los relatos de todas estas mujeres, de las cuales sabemos sólo sus iniciales y el lugar donde fueron detenidas. D e la unión de estos relatos podemos constituir el panorama de lo que fue la vida de esas mujeres durante su detención.

Ya descritas las partes del libro, queremos fundamentar nuestra afirmación de que el discurso testimonial lo atraviesa, independientemente de los géneros que predominan en él. Al hablar de discurso testimonial además de otros géneros, estamos aceptando que el testimonio en sí no es un género. En este punto recogemos la observación de Leonidas M orales, quien sostiene que el testimonio no posee historicidad, característica básica de los géneros literarios ${ }^{1}$. Al ser un discurso transhistórico no es independiente ni puede ser actualizado como los demás géneros, a no ser que sea "como discurso parásito, o incorporado, es decir, desplegado por, y en el interior de, al guno de los discursos genéricos existentes" (M orales, 2001: 25). Y eso es exactamente lo que vemos en N aciste pintada, texto donde predominan los géneros referenciales como la crónica urbana, la biografía, la carta, las memorias, el reportaje, géneros que poseen una relación con el testimonio. Ahora bien, como ya vimos, el relato en primera persona con una gran carga autobiográfica predomina en este texto, lo que nos lleva a afirmar que hay un discurso testimonial ${ }^{2}$ como base de los relatos, incluso en la primera parte que podría considerarse poesía.

D e todas formas, no podemos considerar los testimonios que aparecen en $\mathrm{N}$ aciste pintada como completamente fidedignos. Algunos han sido recogidos por Berenguer, tal como lo advierte en la introducción, principalmente el de las prisioneras políticas. Los testimonios de Brenda están basados en los relatos de dos mujeres prostitutas que han sido ficcionalizados. Las pequeñas historias que van acompañadas por titulares de La Cuarta son, por el contrario, verídicas y corresponden al libro de Teresa Lastra (1997) Las "otras" mujeres, pero el haber sido editados y sacados de contexto confirma nuestra idea de que $\mathrm{N}$ aciste pintada es un texto de corte testimonial 0 al menos con un gran componente de dicho discurso.

La razón por la cual Berenguer se vale del relato testimonial para organizar (o desorganizar) su texto, no nos sorprende si consideramos el rol que el testimonio ha adquirido en la segunda mitad del siglo XX como forma de lucha, como voz de las minorías, tal como afirma Beverly (1991): "W here literature in Latin América has been (mainly) a vehicle for engendering an adult, white,

\footnotetext{
1 Véase Todorov, Genette y Schaeffer, todos en Garrido, M iguel (comp), 1988. Teoría de los géneros literarios. M adrid: Arco.

${ }^{2} \mathrm{~A}$ propósito, son importantes las aclaraciones que sobre el relato testimonial hace M iguel Barnet, en Jara, Renéy Vidal, Hernán (1986).
} 
male patriarcal, 'lettered' subject, testimonio allows the emergence -albeit mediated- of subaltern female, gay, indigenous, black, and proletarian "oral" identities" (19). Es decir, el testimonio intenta darles voz a las minorías. D e esta forma, de la ruptura de la hegemonía de géneros en su obra y utilizando el discurso testimonial como base de ellos, Berenguer alterará el discurso de género sexual, dándole voz a la minoría dentro de la minoría, que es lo que veremos a continuación.

\section{DESPLAZAMIENTO DE LOS GENEROS SEXUALES}

Como afirmamos con anterioridad, la relación entre testimonio y minorías no es algo nuevo. Lienhard (2000) nos recuerda que ya desde la época colonial podemos encontrar textos de este tipo (790). Esto porque una de las características del testimonio es la de dar voz al que ha estado postergado por el poder hegemónico, y en este sentido es que subyace en el testimonio una relación estrecha con la literatura de mujeres y feminista, ya que este tipo de discurso "advierte de la posibilidad de buscar historias que nos permitan tejer las memorias desplazadas de las narrativas hegemónicas" (Forcinito, 2004: 136). Esto corresponde a las intenciones de Berenguer, presente en toda su obra poética, donde no sólo hay un intento de rescate de la voz de los oprimidos, y entre ellos las mujeres, sino también de recobrar memorias y discursos olvidados. En su escritura siempre hay un importante elemento de oralidad que intenta ser rescatado. Como dice la propia autora a propósito de este libro: "mi intención es ficcionalizar la prisión carcelaria entre las hablas" (2000: 197), y estas hablas están constituidas por las realizaciones lingüísticas individuales de diferentes mujeres. En este sentido, creemos que Berenguer trata de crear una polifonía de voces, una dialogicidad, si usamos términos de Bajtín (1982), para crear un contradiscurso a la voz oficial que no suele incluir a esas hablas. N os referiremos primero a una de esas hablas, presente en este libro: la de las prostitutas.

\section{LA PROSTITUTA COMO LO ABYECTO}

Las prostitutas constituyen una voz importante dentro de las hablas que pueblan estelibro, logrando, de esta forma, ser un relato subversivo, no sólo porque ellas son una minoría dentro de la minoría sexual que implica ser mujer, sino por, además, intentar romper la brecha entre las clases sociales; un elemento presente en otras escritoras como D iamela Eltit o Elena Poniatowska. Recordemos que tal como advierte D omitila Barros de C hungara en la tribuna del Año 
Internacional de la M ujer, no todas las mujeres sufren el mismo tipo de discriminación ${ }^{3}$. En este sentido es importante el rol de la editora al, precisamente, ejercer como puente sobre la diferencia de clases ${ }^{4}$. Como afirma Jean Franco (1996): "La mujer intelectual no puede ya sostener ingenuamente que representa a las mujeres y que es su voz, pero puede ampliar los términos del debate político y el uso del privilegio para destruir el privilegio" (113).

Berenguer está consciente de su posición privilegiada y la utiliza haciendo de estas prostitutas, protagonistas. Ella misma, que actúa como una voz escondida en su texto, escribe al final de la sección "Breve narración sobre su ausencia en los motivos nacionales": "Ios personajes femeninos de la novela chilena no tienen existencia, su obsesión metafórica es la familia. Lasmusas son el imaginario de la poesía universal" (109). Por eso ella retrata la vida y los sentimientos de esas mujeres que precisamente no corresponden con el de la mujer en su casa y consagrada a su familia, porque tenerla es algo que le está vedado a la mujer prostituta. El hecho de que a la mujer le esté reservado el rol de "musa" implica su papel pasivo y objetivizante, sin una existencia corpórea y humana fuera del ámbito privado. Al sacar a la figura de la prostituta de su escondite, de ese mundo oculto, Berenguer le da un sitial en el ámbito público y la transforma en sujeto de su propia historia. Este hecho se relaciona con al go que Judith Butler había advertido en su libro Bodiesthat matter (1993): se puede lograr un cambio de paradigma en lo que afecta a las concepciones de identidad mediantela escena pública de lo abyecto. Lo que Butler afirma respecto de la lucha queer, es comparable a lo que Berenguer hace en su libro al presentar las historias, reales o ficcionalizadas, de estas prostitutas: "T his is the politization of abjection in an effort to rewrite the history of the term, and to force it to a demanding resignification" (21). Es valerse de las posibilidades que otorga el relato de corte testimonial y de los diferentes géneros en que éste se actualiza para construir mitologías subversivas.

Es importante aclarar que, en este caso, entendemos por abyecto la definición que K risteva (1989) hace de este concepto: "No es la ausencia de limpieza

\footnotetext{
${ }^{3} \mathrm{M}$ e refiero al citado pasaje en D omitila Barros aclara que ni siquiera en el concepto "mujer" existe igualdad debido a diversos factores principal mente social es: "Señora hace una semana que yo la conozco a usted. C ada mañana usted llega con un traje diferente; sin embargo, yo no. Cada día llega usted pintada y peinada como quien tiene tiempo de pasar en una peluquería bien elegante y puede gastar buena plata en eso; y sin embargo, yo no. Ahora señora, dígame: ¿tiene usted algo semejante a mi situación? ¿Tengo yo algo semejante a su situación de usted? Entonces, de qué igualdad vamos a hablar entre nosotras? ¿Si usted y yo no nos parecemos, si usted y yo somos tan diferentes? Nosotras no podemos en este momento ser iguales, aun como mujeres, no le parece? (Viezzer, 1997: 225).

${ }^{4} \mathrm{~A}$ propósito véase el libro de Pino-0 jeda, Walescka (2000).
} 
o de salud lo que vuelve abyecto, sino aquello que perturba una identidad, un sistema, un orden" (11). En este sentido, la prostituta constituye una importante perturbación al no pertenecer claramente ni al espacio privado ni al público: "T he prostitute comes to synthesize that uneasy positioning of women who are neither allied with a specific domestic site nor formally concealed from public view" (M asiello, 1992: 6).

Esta perturbación al orden queda clara con la cobertura periodística que se le da al caso de "la Chinoska", una mujer lesbiana que asesina a un hombre que atacaba a una de las trabajadoras sexuales de un prostíbulo. Los testimonios que aparecen en el texto de Berenguer contrastan profundamente con los recortes deperiódicos quelos acompañan. En éstosla condición delesbiana de "Chinoska" es retratada como una razón suficiente para odiarla y condenarla. Al pertenecer al círculo de lo que está fuera del orden, de lo que "no debe ser", el discurso público estigmatiza a esta mujer y la muestra como una asesina que mata no por defender a una mujer del abuso, sino que por ser simplemente diferente.

Uno de los titulares dice: "Ninfa asesinó al dueño del prostíbulo de tres puñaladas" (154). O bviamente, la definición de ninfa corresponde a aquella que da el Diccionario de la Real Academia, "mujer de costumbres libres". En todas las partes de la noticia, estas mujeres son tratadas como la peor escoria de la sociedad, sin ningún respeto: "malulas", "ninfas de taco al to, con pelo teñido con jugo de zanahoria", "las locas". Esto se opone a la versión de Clara de las $\mathrm{N}$ ieves M orales, la "C hinoska”, quien cuenta: "Ellas mequieren y me respetan y yo las protejo cuando las tratan mal" (152).

Luego de los testimonios de otros implicados, aparece otra noticia, con fecha 15 de abril de 1991, un año después del primer crimen, del que "C hinoska" logró huir sin ser detenida, cuyo titular consigna: "M ujer policía se disfrazó de prosti y detuvo a lesbiana autora de 2 crímenes" (157). El subtítulo de este titular dice: "Fea, amachada y peligrosa es la famosa C hinoska". Es destacableel hecho de que el ser lesbiana sea incluido en el título, adjetivo que va a la par con "fea y amachada", caracterización clásica de la mujer lesbiana, que corresponde a una imagen estereotípica. Al no cumplir con un requisito básico en el mundo patriarcal, que es tener interés en los hombres, la única posibilidad es que sea "fea y amachada", lo que es reiterado en el cuerpo de la noticia: "M alaza, peligrosísima, fiera para los tajos o para manejar revólveres, fea hasta decir basta, con un aspecto de macho que no se la puede, es la lesbiana detenida por Investigaciones". U na vez más, Chinoska corresponde a lo abyecto: "Aquello que no respeta los límites, los lugares, las reglas. La complicidad, lo ambiguo, lo mixto. El traidor, el mentiroso, el criminal con la conciencialimpia, (...) el asesino que pretende salvar" (K risteva, 1989: 11), y por eso es relegada y condenada por la opinión pública, más por su condición sexual (unida a la de ser mujer y prosti- 
tuta) que por sus crímenes. Tal como afirmara Butler (1993), el sexo es una material ización denormas reguladorasque son las de la hegemonía heterosexual, en la que los cuerpos abyectos o desl egitimados dejan de ser considerados como cuerpos. "La C hinoska" representa lo abyecto, lo rechazado, la minoría dentro de la minoría (mujer, prostituta y lesbiana), a la que Berenguer da el lugar de protagonista, dándole así también la oportunidad de tener voz y contar su versión de los hechos.

La última sección de esta parte, como ya hemos señalado, la constituyen los testimonios de otras prostitutas, tomados del libro de Teresa Lastra, alternados con diversos titulares del diario La Cuarta. Berenguer en esta sección trata de desestabilizar la visión hegemónica, no sólo con la alternancia de voces, sino por medio del pastiche, forma bastante utilizada por muchas escritoras latinoamericanas (Franco, 1996). Estas historias de vida están en el libro de Lastra ordenados por temas y precedidos por una introducción teórica y estadística que da cuenta de los resultados de las entrevistas realizadas. En el texto de Berenguer los relatoshan sido mezclados y no poseen ningún título ni pasaje introductorio ${ }^{5}$. A veces van precedidos de un titular de diario que contrasta con el relato de las mujeres, ya que no guarda relación directa con ellos. Lo único que los titulares comparten entre sí es la temática: la agresión sexual y la violencia contra las mujeres.

La tragedia de la vida de estas mujeres se constituye en una voz disonante al contrastar con los titulares que presentan hasta la violación como algo jocoso. También hay una contradicción entre las noticias que pertenecen al ámbito público y las historias personales de estas mujeres y los relatos de su niñez, sus familias y sueños. Los titulares parecen impersonales, llenos de apodos, mientras las historias de las mujeres llevan siempre un nombre, aquél que les está vedado en el espacio público.

Berenguer, al mezclar estos textosy contrastar los distintos géneros discursivos, logra un efecto conmovedor: la imagen pública dela mujer aparece disociada de la de sus sentimientos privados, sentimientos que hasta la más antigua de las prostitutas posee y que, sin embargo, el discurso público parece sustraerle.

\footnotetext{
${ }^{5}$ Consideramos que hay en la versión de Berenguer una dobletransgresión al discurso hegemónico, si tenemos en cuenta queel "relato de vida" ha sido recogido por las ciencias sociales como un medio de reconstruir la historia y la memoria colectiva integrando las voces de los marginados. Como afirman Guerray Skewes: "En su relato, los sujetos de las historias de vida muestran las contradicciones a las que se les somete en su exclusión. Revelan sus prácticas de resistencia, y de acomodación y transformación silenciosa de las imposiciones a las que no pueden sustraerse" (1999: 179). Es decir, el texto de Lastra ya rompe el orden hegemónico al integrar los discursos de las prostitutas y el texto de Berenguer viene a ser una segunda versión del texto, una transgresión a la transgresión.
} 


\section{LA PRISIONERA POLITICA}

La tercera y última parte de $\mathrm{N}$ aciste pintada se titula C asa inmóvil, con el subtítulo "Recados de la prisión (1980-1990)", y comienza con "Recado de Chile: a Sybila Arredondo", la viuda de JoséM aría Arguedas, quien estuvo más de catorce años en cárceles peruanas acusada de actividades terroristas. En ella, Berenguer le confiesa a Arredondo su "deseo de rescatar el recado como género" (190). El texto está encabezado por un epígrafe de G abriela M istral, de quien Berenguer toma la idea del recado: " $\mathrm{H}$ ay palabras que sofocadas, hablan más, precisamente por el sofoco y el exilio, y la de 'paz' está saltando hasta las gentes sordas 0 distraídas" (190).

Si revisamos brevementelo queel género del recado significaba para Gabriela M istral, nos encontraremos que, tal como afirma M aría Ester M artínez (1996), hay en ellos una heterogeneidad, una mezcla de discursos privados y públicos, y eso es lo que Berenguer rescata en este trabajo. Como dice M artínez, a diferencia de la carta y la prosa corta, para M istral "el recado no requiere de una respuesta para ser comprendido cabalmente, porque no es un fragmento de una conversación ni tampoco un escrito discontinuo; es un todo completo en sí y por sí mismo, con una hipótesis que se va demostrando a medida que se despliega ante los ojos del lector" (85). Esto es significativo porque aunque los testimonios de las presas políticas que recoge Berenguer no poseen una hipótesis, sí hay un sentido en su relato que el público lector está llamado a completar.

Así, los recados que ella recoge no son propiamente tales, sino más bien corresponden al testimonio de varias presas políticas que ella ha ficcionalizado y ordenado en forma de cartas de distintas voces que a veces se repiten, y de sus vivencias en los distintos centros de detención en que se encontraron: el C entro de O rientación Femenina o Casa Correccional, llevado por unas monjas; la cárcel de hombres de San M iguel; la casa detortura ubicada en Borgoño 1470 y algunos otros centros de detención en Curicó, Santo D omingo y Q uillota.

El valor de recoger estos testimonios es múltiple: por un lado intenta recuperar una memoria perdida y hacer que no se olvide lo que ocurrió, a la vez que es una forma de reconstruir la historia másallá de la historia oficial. Por otra parte, Berenguer trata de rescatar la figura de la mujer militante, la cual ha ocupado siempre un rol secundario, particularmente en $\mathrm{Chile.} \mathrm{N}$ i siquiera en el discurso progresista de la U nidad Popular se le da un lugar de importancia a la mujer, quien no es incluida en las demandas de los partidos políticos, pues el proyecto socialista estaba enfocado en asuntos de clase y no de género:

Se les plantea subvertir el orden de la relación dominante-dominado, en circunstancias en que ella permanecerá siendo la dependiente compañera de un 
hombre libre. El proyecto político popular propone al hombreel umbral dela libertad; para las mujeres, la libertad no termina de traspasar el umbral de la casa (Kirkwood, 1996: 53).

La mujer, entonces, seguía ocupando un rol pasivo, de apoyo al guerrillero, pero nunca como protagonista de un cambio social, ya queincluso al interior de sus partidos (si participaban en alguno) ocupaban un rol secundario, realizando labores domésticas. A pesar de que las mujeres adquirieron un rol importante en el proceso de lucha contra la dictadura, siemprese alude a las madres de detenidos desaparecidos, pero poco se habla de la mujer militante, de la detención que muchas sufrieron y de la tortura. Como afirma Forcinito, "las mujeres quedaron desplazadas de la narrativa del protagonismo revolucionario" (150). El darles voz para contar sus experiencias, es traspasar sus vivencias al ámbito de lo público. Las mujeres que estuvieron presas relatan precisamente lo doblemente difícil que era enfrentar la prisión, precisamente por su condición de mujeres.

Por una parte estaba la relación con los torturadores, entes anónimos que ellas no veían por estar vendadas, y por otra, su relación con los gendarmes y carabineros una vez que ya habían sido trasladadas a la cárcel. Una de ellas cuenta de esta discriminación:

me decían: ¿Andas pololeando, que andas preocupada de estar metida en tonteras? ... a mí me sacan eso, pero que le van a sacar a una mujer que es mayor: ah! tú estás viejay deberías estar criando hijos en vez de andar hueveando en política. Y más encima tú por ser mujer es peor (...) pero además yo creo que el mismo hecho de que la mujer es como históricamente no protagonista (294).

Complicaba mucho más esta situación, el hecho de queal principio, y antes de ser reconocidas como presas políticas, las mujeres fueron enviadas a la cárcel de hombres deSan M iguel, debiendo allí lidiar con la presencia constante de los presos, que eran delincuentes comunes:

Cuando salíamos al patio, ellos estaban en las ventanas, masturbándose. Estabas obligada a escuchar, mirar y tolerar. En general no duermen, toda la noche gritan cosas obscenas. Ahí descubría la diferencia entre un garabato y una grosería. N os gritaban palabras muy sucias relacionadas con el sexo femenino, así el grado de agresión era sin tregua. En su más despreciable nivel la lengua es extrema de violenta. El sexo lo hacen por la boca (203).

La agresión a las mujeres era doble, porque no sólo eran agredidas por su condición de políticas, es más, ni siquiera les era reconocido ese rol: eran ante todo mujeres cuyo deber era cuidar de su familia. Fuera del encarcelamiento, sufrían las agresiones verbales de hombres que no las consideraban personas 
sino cuerpos, y sobre sus cuerpos, está el poder ejercido por el Estado a través de la tortura, haciéndolas, al decir de Foucault (1991), cuerpo dócil. Sin embargo, esta misma condición de mujeres les permitió sobrellevar la prisión de mejor modo que sus compañeros hombres. El hecho de que ellas no tuvieran un rol importante en sus partidos, unido a su capacidad de expresar sus sentimientos algo que sí le está permitido a la mujer en el sistema patriarcal- les otorgó la posibilidad de revertir esta situación y crear lazos, afectos, más allá de los partidos políticos. Así, como cuenta M .0 .: "M uchas veces no respondimos a los llamados partidarios y buscamos la forma de resolver nuestros problemas a través de lo que nos unía construyendo relaciones interpersonales, humanas y afectivas dentro del grupo cerrado de mujeres en la cárcel" (193). Y luego agrega: "Los compañeros no se ponían de acuerdo, la mitad sí, la otra mitad no. Eran obedientes en sus orgánicas. M i compañero, el padre de mis hijos, estaba en la cárcel, por eso conozco el problema. El se relacionaba políticamente, sólo hablaba de proyectos, de conducciones, de proceso, nunca habló detristezas, de dolores, de las preocupaciones para al imentar a sus hijos" (193).

Este testimonio deja en claro la división de roles. Las mujeres no dejaban de ser madres y esposas mientras estaban detenidas; los hombres, en cambio, cumplían con el perfil del hombre político guerrillero, con "una misión superior", lo que complicó su situación afectiva. La misma M .0 . dice que su marido lehabía dicho "hice un paréntesis en mi vida, congelé mis sentimientos"(194), algo que a ella le parecía inconcebible.

También a muchas les facilitó el hecho de tener un pensamiento feminista, ya que no consideraban el estar prisioneras como una pérdida mucho mayor a la vivida a diario. Así, A.M .: cuenta:

Cuando me despojaron de mis ropas, de mis objetos, no me pareció tan terrible, porque ¿tuveal go mío propio al guna vez? Es cierto que perdí la noción del tiempo, tenía que reubicarme a cada instante. Es cierto que mi identidad estabasiempreal límite, pero luego mepregunto si realmentetuveun lugar. Como dice la M iriam que nosotras mujeres salimos con una experiencia carcelaria, y más enteras quelos hombres. Es cierto, pero ¿no hemos estado siempre privadas? (201).

Por otra parte, la solidaridad de género que hubo en la cárcel les sirvió a todas para sobrellevar el encierro y el maltrato demejor manera. Como ejemplo de ello, podemos mencionar que las presas, al saber que una nueva detenida llegaba a la cárcel y que iba a enfrentar desde 30 a 60 días de aislamiento, se ponían de acuerdo para cantarle, para que se sintiera acompañada, cuenta M .0 .: "Para la que se encontraba incomunicada esto era muy preciado. En una oportunidad supimos que una compañera socialista había llegado y le cantamos el 
himno del partido, ella no podía creerlo. Esa mujer nosama hasta el día de hoy" (205). M uchas hablan del surgimiento de amistades y relaciones que perduran en el presente. Pero no todas lograron conservar su salud mental. Varias sufrieron de depresión, e incluso se habla mucho de Patricia R., quien desarrolló problemas mentales durantesu estadía en la cárcel. Por razones obvias, Berenguer no consigna su testimonio en este libro, pero sí el de varias otras prisioneras, incluyendo su hermana, que cuentan delas actitudes, hablas y el deterioro sufrido por Patricia. Aquí nos encontramos con otro tipo de testimonio, por tratarse de otro tipo de testigo: el musulmán.

En su libro L o quequeda deAuschwitz, Giorgio Agamben (2000), basándose en el testimonio de Primo Levi sobre los campos de concentración, hace un análisis de los distintos tipos de testigo: el superviviente, el que cuenta lo que vivió; y el musulmán, aquél que ya no puede testimoniar. Dice Agamben:

El testigo testimonia de ordinario a favor de la verdad y de la justicia, que son las que prestan a sus palabras consistencia y plenitud. Pero en este caso el testimonio vale en lo esencial por lo que falta en él; contiene, en su centro mismo, algo que es intestimoniable, que destruye la autoridad de los supervivientes. Los "verdaderos" testigos, los "testigos integrales" son los que no han testimoniado ni hubieran podido hacerlo. Son losque "han tocado fondo", Ios musulmanes, los hundidos (34).

D e esta forma, la presencia de Patricia, que equivale al musulmán, adquiere especial relevancia, y Berenguer sela da, ya que dedica gran parte de los testimonios a los relatos sobre ella. Se detiene en mostrar su figura completamente marginal en la cárcel. A pesar de que ella puede hablar, un día deja de hacerlo. Así dice su hermana: "inesperadamente tiene un vuelco. Se silencia, se mete para dentro, participa poco o nada de la vida cotidiana de la cárcel"(221). Luego vuelve a hablar, pero como cuenta D.B., no se comunica con el resto:

El que hablara sola, porque ella hablaba consigo misma y yo la observaba y pensaba, eso es la locura, pensaba mientras la miraba, es ésa una tremenda soledad, pero lo sabe ella y si no lo sabe, entonces, me decía en cierto modo, qué bueno es estar fuera de sí. Y la seguía mirando como se depilaba en circunstancia de que no tenía ningún pelo, ni en las piernas ni debajo de los brazos, ni en las cejas, ni en la cabeza. Entonces, para mí, ella era un espejo de nosotras, al mismo tiempo que era nuestra alteración a la rutina (264).

El relato de D.B. nos muestra que a pesar de que Patricia se hubiera marginado de la vida carcelaria, su figura era central en ella: "era un espejo de nosotras", del sufrimiento y la soledad que tal vez muchas sentían, pero era a la vez la diferencia, "la otra" en un mundo compartido sólo con otras mujeres, el reflejo 
de lo queellas podían llegar a ser dentro de la cárcel y delo que son fuera de ella: alienadas por su condición de minoría .

\section{CONCLUSION}

A lo largo de este trabajo creemos haber ilustrado cómo Carmen Berenguer altera la hegemonía de los géneros literarios y se vale del discurso testimonial y de recursos como el pastiche y el collage, para alterar también la hegemonía del discurso patriarcal.

Al dar voz y cabida a los relatos de las prostitutas, Berenguer no sólo rompe los límites de los público y privado sino que nos permite como lectores realizar nuestra propia interpretación de las diferencias que existen entre estos discursos. Un ejemplo de ello es el contraste entreel testimonio delas prostitutas y los titulares de los diarios, donde podemos constatar dos realidades completamente distintas: la oficial y la que viven día a día estas mujeres.

En el caso de las prisioneras políticas, sus historias nos revelan su dolor, su lucha y fortaleza para enfrentar, en muchos casos, la pérdida de sus parejas e hijos y la vida en la prisión, siendo clave para sobrellevar esta experiencia su capacidad de organizarse, de crear lazos humanos más allá de los partidos, algo muy distinto a lo ocurrido a los prisioneros políticos hombres. La falta de reconocimiento y el rol secundario de la mujer en la lucha política les dio espacio para expresar sus sentimientos, para entender y solidarizar con sus compañeras.

Final mente, es destacable la variedad de voces de que Berenguer se vale para crear su obra. Naciste pintada es una concurrencia de distintas hablas, de diferentes discursos: una construcción dialógica donde la voz de la mujer adquiere un nuevo valor, porque sobrepasa espacios y roles predeterminados.

\section{REFERENCIAS}

Agamben, Giorgio. 2000. Lo que queda de Auschwitz. El archivo y el testigo. Traducción de Antonio Gimeno Cuspinera. Valencia: Pre-Textos.

Bajtín, M ijail. 1982. Estética de la creación verbal. M éxico: Siglo XXI.

Barnet, M iguel. 1986. "Testimonio y comunicación: una vía hacia la identidad", en Jara, René y Vidal, Hernán (comp.) Testimonio y literatura. M inneapolis, USA: Institute for the Study of Ideologies and Literature, pp. 303-314.

\footnotetext{
${ }^{6}$ Es interesante notar que dos personajes tan relevantes en el libro de Berenguer sufran de una triple marginalidad: Chinoska por ser mujer, prostituta, lesbiana, y Patricia por ser mujer, presa política y "musulmán".
} 
Berenguer, C armen. 1999. Naciste pintada. Santiago, Chile: Cuarto Propio.

,------ . 2000. "Recados de la prisión en las fisuras del poder", en Escrituras de la diferencia sexual. Raquel O lea (Ed.) Santiago, Chile: Lom.

Beverly, John. 1991. "Through all things modern: Second thoughts on testimonio", en Boundary 2, pp. 1-21.

Butler, Judith. 1993. Bodies that matter. On the discursive limits of sex. N ueva York: Routledge.

Forcinito, Ana. 2004. M emorias y nomadías: géneros y cuerpos en los márgenes del posfeminismo. Santiago, Chile: Cuarto Propio.

Foucault, M ichel. 1991. D isciplineand punish: Thebirth of theprison. H armondsworth: Penguin Books.

Franco, Jean. 1996. M arcar diferencias, cruzar fronteras. Santiago, C hile: Cuarto Propio.

Garrido, M iguel. 1988. (comp.) Teoría de los géneros literarios. M adrid: Arco.

Genette, Gerard. 1988. "Géneros, tipos, modos", en Garrido, M iguel (comp.) Teoría de los géneros literarios. M adrid: Arco, pp. 183-233.

Guerra, D. y Skewes, JC. 1999. "La historia de vida como contradiscurso: Pliegues y repliegues de una mujer", en Proposiciones 29, pp. 178-189.

Jara, Renéy Vidal, H ernán (comp.) 1986. Tetimonio y literatura. M inneapolis, USA: Institute for the Study of Ideologies and Literature.

Kirkwood, Julieta. 1996. Ser política en Chile: Los nudos de la sabiduría feminista. Santiago, Chile: Cuarto Propio.

Kristeva, Julia. 1989. Poderesdela perversión. Buenos Aires: Siglo XXI, segunda edición.

Lastra, Teresa. 1997. Las "otras" mujeres. Santiago, C hile: Gráfica alternativa.

Lienhard, M artín. 2000 "Voces marginadas y poder discursivo en América Latina”, en Revista Iberoamericana 193, pp. 784-798.

Lyotard, Jean François. 2000. La condición posmoderna: Informesobreel saber. M adrid: Cátedra.

M artínez, M aría Ester. 1996. "Crítica literaria en recados de Gabriela M istral", en Taller de Letras ( $\mathrm{N}$ o especial), pp. 79-86.

M asiello, Francine. 1992. "Women, state, and thefamily in Latin American literature", en Women, culture, and politics in Latin America: Seminar on feminism and culture in Latin America. Bergmann, M asiello, N ewman (eds.). Berkeley: University of California Press.

M orales, Leonidas. 2001. La escritura deal lado. G éneros referenciales. Santiago, Chile: Cuarto Propio.

Partnoy, Alicia. 1986. ThelittleSchool: tales of disappearance and survival. San Francisco: M idnight.

Pino-O jeda, Walescka. 2000. Sobre castas y puentes: Conversaciones con Elena Poniatowska, Rosario Ferréy D iamela Eltit. Santiago, C hile: Editorial Cuarto Propio.

Schaeffer, Jean-M arie. 1988. "D el texto al género. N otas sobre la problemática genérica", en M iguel Garrido (comp.) Teoría delos génerosliterarios. M adrid: Arco, pp. 155-179.

Todorov, Tzvetan. 1988. "El origen de los géneros", en M iguel Garrido (comp.) Teoría de los géneros literarios. M adrid: Arco, pp. 31-48.

Viezzer, M oema. 1997. Si me permiten hablar... Testimonio de D omitila, una mujer de las minas de Bolivia. M éxico: Siglo XXI. 